\title{
Determining Public Opinion of the COVID-19 Pandemic in South Korea and Japan: Social Network Mining on Twitter
}

\author{
Hocheol Lee ${ }^{1}$, Eun Bi Noh ${ }^{2}$, Sea Hwan $\mathrm{Choi}^{3}$, Bo Zhao ${ }^{1}$, Eun Woo Nam ${ }^{4}$ \\ 'Department of Health Administration, Graduate School of Yonsei University, Wonju, Korea \\ ${ }^{2}$ Department of Spatial-temporal Epidemiology, Graduate School of Public Health, Seoul National University, Seoul, Korea \\ ${ }^{3}$ Department of Applied Statistics, Graduate School of Yonsei University, Wonju, Korea \\ ${ }^{4}$ Department of Health Administration, College of Health Science, Yonsei University, Wonju, Korea
}

Objectives: This study analyzed the perceptions and emotions of Korean and Japanese citizens regarding coronavirus disease 2019 (COVID-19). It examined the frequency of words used in Korean and Japanese tweets regarding COVID-19 and the corresponding changes in their interests. Methods: This cross-sectional study analyzed Twitter posts (Tweets) from February 1,2020 to April 30, 2020 to determine public opinion of the COVID-19 pandemic in Korea and Japan. We collected data from Twitter (https://twitter.com/), a major social media platform in Korea and Japan. Python 3.7 Library was used for data collection. Data analysis included KR-WordRank and frequency analyses in Korea and Japan, respectively. Heat diagrams, word clouds, and rank flowcharts were also used. Results: Overall, 1,470,673 and 4,195,457 tweets were collected from Korea and Japan, respectively. The word trend in Korea and Japan was analyzed every 5 days. The word cloud analysis revealed "COVID-19", "Shinchonji", "Mask", "Daegu", and "Travel" as frequently used words in Korea. While in Japan, "COVID-19", "Mask", "Test", "Impact", and "China" were identified as high-frequency words. They were divided into four categories: social distancing, prevention, issue, and emotion for the rank flowcharts. Concerning emotion, "Overcome" and "Support" increased from February in Korea, while "Worry" and "Anxiety" decreased in Japan from April 1. Conclusions: As a result of the trend, people's interests in the economy were high in both countries, indicating their reservations on the economic downturn. Therefore, focusing policies toward economic stability is essential. Although the interest in prevention increased since April in both countries, the general public's relaxation regarding COVID-19 was also observed.

Keywords: Pandemics, Data Mining, Coronavirus, Communicable Diseases, Social Networking

Submitted: July 16, 2020, Revised: September 18, 2020, Accepted: September 22, 2020

\section{Corresponding Author}

Eun Woo Nam

Department of Health Administration, College of Health Science, Yonsei University, 1, Yeonsedae-gil Heungeop-myeon, Wonju 26493, Korea. Tel: +82-33-760-2413, E-mail: ewnam@yonsei.ac.kr (https://orcid.org/0000-0001-6584-0658)

This is an Open Access article distributed under the terms of the Creative Commons Attribution Non-Commercial License (http://creativecommons.org/licenses/by-nc/4.0/) which permits unrestricted non-commercial use, distribution, and reproduction in any medium, provided the original work is properly cited.

(C) 2020 The Korean Society of Medical Informatics 


\section{Introduction}

Following the novel coronavirus disease (COVID-19) outbreak in Wuhan, China, in December 2019, COVID-19 had spread rapidly to other countries, including Korea and Japan, two of the closest countries to China. Korea and Japan's first confirmed case was reported on January 19, 2020 and January 16, 2020, respectively. Considering its severity, the World Health Organization declared this disease as a pandemic on March 11, 2020 [1].

By April 30, 2020, the incidence rate of COVID-19 in Korea (10,765 confirmed cases, 247 deaths) and Japan (14,119 confirmed cases, 435 deaths) showed downward trends, due to the responses of both governments [2]. However, the physical and psychological stress among the general public has continued, given the continued occurrence of new confirmed cases. Psychological counseling services have reportedly increased after the emergence of COVID-19 due to the increased incidence of depression and excessive stress [3-5]. Previous studies also indicated the possibility of increased distress and psychological fatigue among the general public due to the escalation of governmental regulations [6].

In response, the Korean government announced "psychological quarantine" on March 6 for the psychological stress induced by COVID-19. Their National Trauma Center (http://nct.go.kr) provides "COVID-19 Integrated Psychological Support Group", "Ways to keep good mental health", and "Counseling services to patients and their parents" [7]. The Japanese Ministry of Health, Labor, and Welfare has implemented psychological treatment \& support projects in response to COVID-19. They provide counseling in the form of a chat called "Consultation of the social network services (SNS) mind related to COVID-19" [8]. While these nationallevel mental health/stress policies should be implemented after properly identifying citizens' mental health conditions, stress, and needs concerning COVID-19, previous studies showed that the COVID-19 mental health policies in Korea and Japan lacked information about these needs $[9,10]$. People from different countries show different reactions to the COVID-19 pandemic due to their different sensitivities, government responses, and psychological support; thus, consideration of these diverse aspects is critical [11-13].

In recent years, Internet and smartphone usage has increased rapidly, and social media platforms function as new modern forms of communication. More than $60 \%$ of Koreans use the Internet for social networking, and more than $50 \%$ of Japanese reported using more than one SNS platform. As a major social media platform, previous studies analyzed the perceptions and emotional status of the public through Twitter, which showed that social media platforms could reflect users' emotional states [14].

This study analyzed the perceptions and emotions of Korean and Japanese citizens regarding COVID-19. It analyzed the frequency of words used in Korean and Japanese tweets related to COVID-19 and the corresponding changes in their interests. It also aimed to provide evidence to establish the COVID-19 mental health policies of both governments.

\section{Methods}

\section{Study Design}

This cross-sectional study analyzed Twitter posts (Tweets) from February 1, 2020 to April 30, 2020 to determine public opinion regarding the COVID-19 pandemic in Korea and Japan.

\section{Data Collection}

We collected data from Twitter (https://twitter.com/), a major social media platform in Korea and Japan, between February 1, 2020 and April 30, 2020. Search terms to collect tweets (posts on Twitter) included "corona (코로나)" in Korean and "corona (コロナ)" in Japanese. Python 3.7 Library (Beautifulsoup and GetOldTweet3) was used for data collection. Due to a large number of tweets in Japan, we limited the daily collected data to 50,000 tweets.

The number of tweets collected in Korea and Japan was $1,470,673$ and 4,195,457, respectively. The collected tweets were then classified into words using morphology analysis, and nouns and hashtags were extracted. After the morphology analysis, duplicate and irrelevant words were removed. The final analysis included 1,244,923 and 3,706,366 tweets from Korea and Japan, respectively (Figure 1).

\section{Statistical Analysis}

After the data collection, we used three kinds of statistical analysis. First, we used the KR-WordRank analysis in Korea and frequency analysis in Japan. Given the difficulties related to the text-mining analysis of the Korean language due to the ambiguity of spacing words, the fitness of domain, and postposition such as "eun", "neum", "iga" [15], the KRWordRank method, used widely in previous studies, was selected for analysis. The KR-WordRank is one of the textmining approaches which performs unsupervised word segmentation. It can be divided into the exterior boundary value (EBV), which represents the probability of words around the central word, and the interior boundary value 


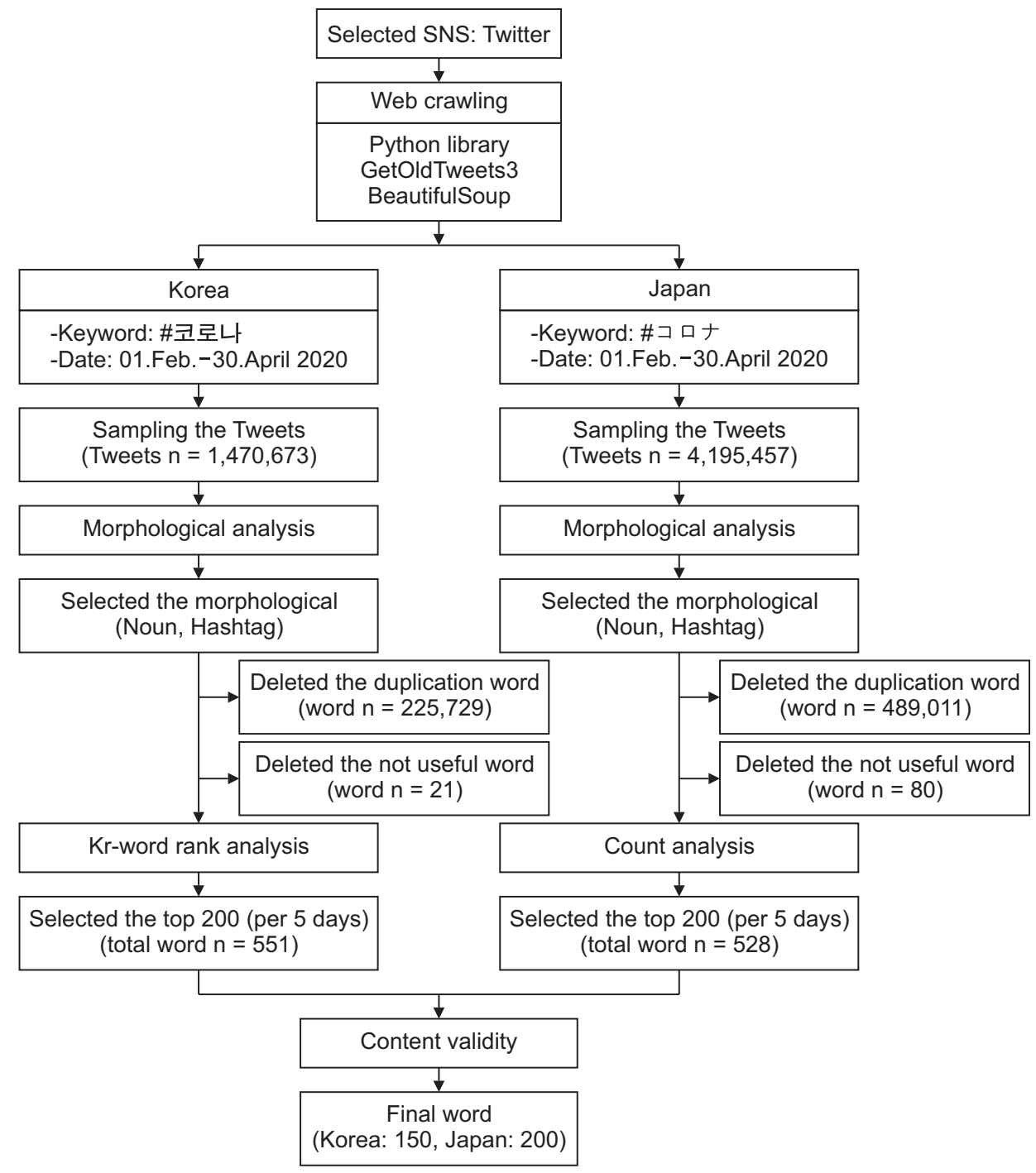

Figure 1 . Web crawling flow chart.

(IBV), which shows the cohesion of continuation characters related to the central word. After the EBV is derived and reinforced through the EBV of neighboring words, each EBV is calculated, reinforced by the relationship between the words, and mutually strengthened through the EBV of adjacent words. In contrast, IBV is scored by words' importance using mutual information (MI), which calculates the continuous probabilities of characters. Through this process, the KR-WordRank ranks by their importance in the network. For Japanese tweets, frequency analysis was more suitable because Japanese words are easily recognized. Moreover, frequency analysis has the advantages of high computation speed and easy access. Through the analysis, we estimated the changes of frequency using each word over time. Following the KR-WordRank analysis, the data from February 1, 2020 to April 30, 2020 were visually represented through the "heat diagram".

Second, we used "Word Cloud" to analyze word frequency from February 1, 2020 to April 30, 2020 in Korea and Japan. Third, we analyzed the rank flowcharts by categorizing the words into four types (social distancing, prevention, issue, and emotion) in both Korea and Japan.

\section{Results}

\section{Crawling Data Characteristics}

This study collected a total of 2,965,770 tweets, including 1,470,313 tweets from Korea, and 4,195,457 tweets from Japan. Since we had limited the daily tweets in Japan to 50,000, 250,000 tweets were the maximum data collected in 5 days. In Korea, 371,051 corona-related tweets from February 21, 2020 to March 1, 2020 accounted for 25.2\% of all tweets. On the other hand, 13,943 tweets from March 12-16 accounted for $0.9 \%$, which was the lowest (Table 1 ). 
Table 1. The frequency of crawling data in Korea and Japan from February 1, 2020 to April 30, 2020

\begin{tabular}{|c|c|c|c|c|}
\hline \multirow{2}{*}{ Date } & \multicolumn{2}{|c|}{ Korea } & \multicolumn{2}{|c|}{ Japan $^{a}$} \\
\hline & Tweets & $\%$ & Tweets & $\%$ \\
\hline 02/01/2020-02/05/2020 & 41,581 & 2.8 & 250,000 & 6.0 \\
\hline 02/06/2020-02/10/2020 & 36,405 & 2.5 & 227,757 & 5.4 \\
\hline $02 / 11 / 2020-02 / 15 / 2020$ & 28,011 & 1.9 & 250,000 & 6.0 \\
\hline 02/06/2020-02/20/2020 & 65,816 & 4.5 & 250,000 & 6.0 \\
\hline $02 / 21 / 2020-02 / 25 / 2020$ & 182,210 & 12.4 & 250,000 & 6.0 \\
\hline 02/26/2020-03/01/2020 & 188,841 & 12.8 & 250,000 & 6.0 \\
\hline 03/02/2020-03/06/2020 & 106,231 & 7.2 & 151,900 & 3.6 \\
\hline 03/07/2020-03/11/2020 & 126,172 & 8.6 & 176,760 & 4.2 \\
\hline 03/12/2020-03/16/2020 & 13,943 & 0.9 & 209,760 & 5.0 \\
\hline $03 / 17 / 2020-03 / 21 / 2020$ & 42,789 & 2.9 & 250,000 & 6.0 \\
\hline $03 / 22 / 2020-03 / 26 / 2020$ & 104,893 & 7.1 & 250,000 & 6.0 \\
\hline $03 / 27 / 2020-03 / 31 / 2020$ & 106,249 & 7.2 & 229,280 & 5.5 \\
\hline 04/01/2020-04/05/2020 & 97,669 & 6.6 & 250,000 & 6.0 \\
\hline 04/06/2020-04/10/2020 & 92,642 & 6.3 & 250,000 & 6.0 \\
\hline $04 / 11 / 2020-04 / 15 / 2020$ & 74,104 & 5.0 & 250,000 & 6.0 \\
\hline $04 / 16 / 2020-04 / 20 / 2020$ & 63,115 & 4.3 & 250,000 & 6.0 \\
\hline $04 / 21 / 2020-04 / 25 / 2020$ & 54,590 & 3.7 & 250,000 & 6.0 \\
\hline $04 / 26 / 2020-04 / 30 / 2020$ & 45,052 & 3.1 & 200,000 & 4.8 \\
\hline Total & $1,470,313$ & 100 & $4,195,457$ & 100 \\
\hline
\end{tabular}

${ }^{\mathrm{a}} 50,000$ maximum tweets per day.

\section{Heat Diagram}

Figures 2 and 3 present the word trend in Korea and Japan for every 5 days from February 1, 2020 to April 30, 2020. In Korea, the words "COVID-19 (코로나)" and "News (뉴스)" were consistently high since February, while "MERS (메르 스)" appeared on Twitter until February 10 and then disappeared. "Shincheonji (신천지)" first appeared on February 15 and continued to rank high until April 30. “Travel (여행)" was highly ranked on February 5 but disappeared after February 20. "Online (온라인)" first appeared on April 5, and its rank increased gradually until April 30 (Figure 2).

In Japan, “COVID-19 (Corona)”, “Impact (影響)”, “Mask (マスク)”, “China (中国)”, “Response (対応)”, “Economy (経 済)”, and “Government (政府)” continuously ranked high from February 5 to April 30. The word “Olympics (オリンピ ツク)” was not in the rankings from February 29 to March 10 but gradually increased from March 15 to April and became a high ranked word in April. The rank of "Washing hands (手洗い)” decreased from March, but increased again from April 20 (Figure 3).

\section{Word Cloud}

Figure 4 presents the results of the word cloud analysis of the Korean and Japanese tweets from February 1 to April 30, 2020. In Korea, “COVID-19", "Shinchonji”, "Mask”, “Daegu”, and "Travel” occurred frequently. In Japan, "COVID-19", "Mask", “Test”, "Impact”, and "China” were identified as highfrequency words.

\section{Rank Flowchart}

We analyzed the rank flowcharts of the Korean and Japanese tweets from February 1, 2020 and divided them into four categories, namely, social distancing, prevention, issue, and emotion (Figure 5).

\section{1) Social distancing}

In Korea, the rank of "World" increased from March 4, while the rank of "Travel" decreased after February 26. Since April, the word "Online" appeared and continuously increased in rank. In Japan, the rank of "Going out" and "Home" continuously increased from February 13 and February 19, while the rank of "Postpone" decreased.

\section{2) Prevention}

In Korea, the rank of "Mask" was consistently high. The rank of "Prevention" decreased after February 12 and increased again after April 15. In Japan, the rank of "Mask" was consistently high, while the ranks of "Washing hands" and "Disinfection" decreased. The rank of "Prevention" began to increase after March 25.

3) Issue

In Korea, "Shinchonji" and "Daegu" continuously ranked high from February 19. The word "Donation" decreased from March 4 to March 25, after which it increased. Additionally, the ranking of "Economy" showed an upward trend since March 25. In Japan, "Economy” increased since February and reached the highest rank on March 11. The word "Olympics" rapidly decreased since February 26, and then increased from March 11.

\section{4) Emotion}

In Korea, "Government" was ranked 10th, "Overcome" continued to increase after February 26, and the rank trend for "Support" changed from decreasing to increasing from February 12 to March 16. In Japan, the rank of "End" rose since February and ranked in the top 10, while "Worry" and "Anxiety" decreased from April 1. 


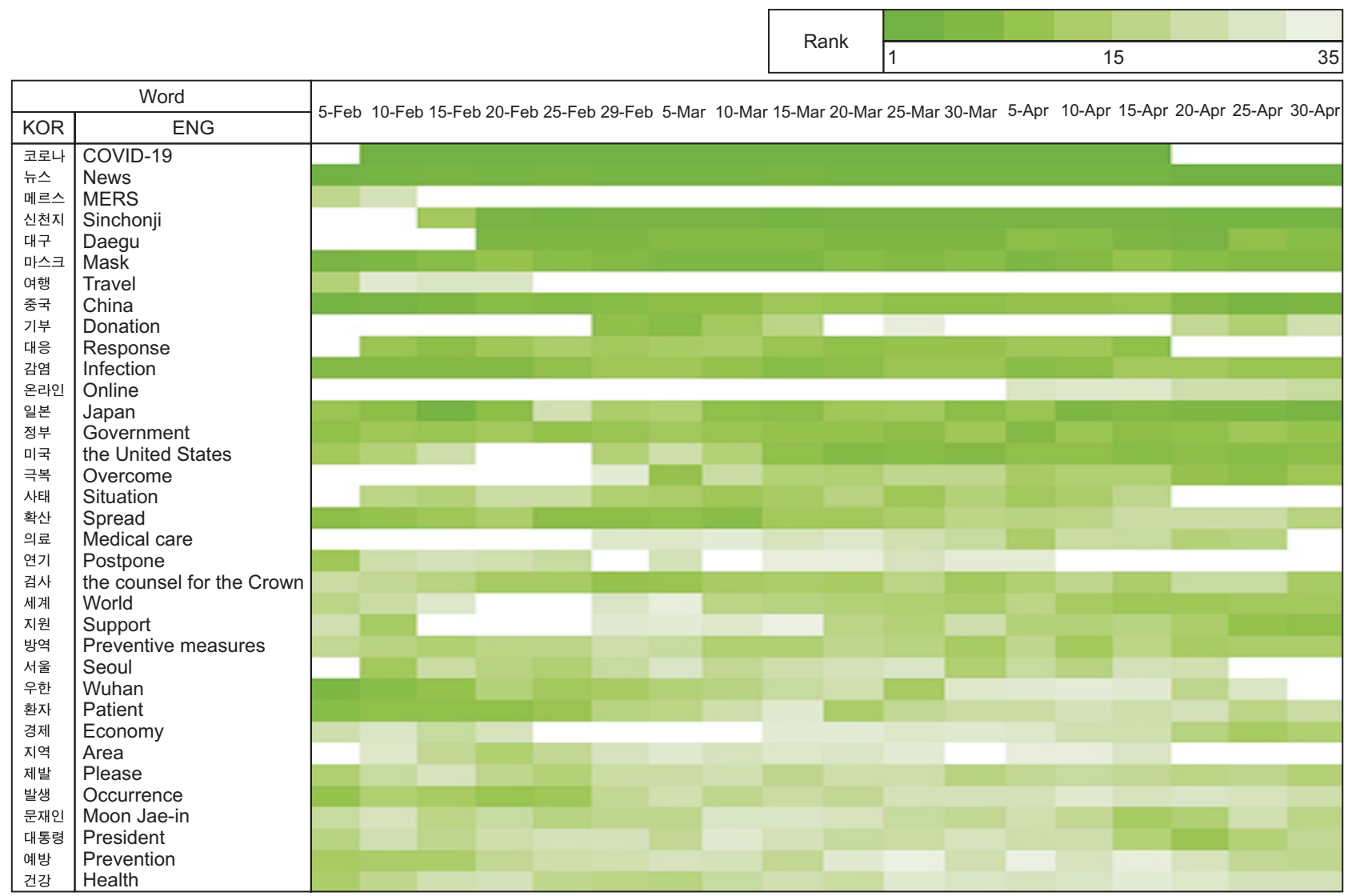

Figure 2. Heat diagram on the coronavirus disease 2019 (COVID-19) word trend in Korea from February 1, 2020 to April $30,2020$.

\section{Discussion}

This study analyzed the perceptions and emotions of Korean and Japanese citizens about COVID-19 to gain insight for future COVID-19 responses.

There was a difference in the number of tweets between Korea and Japan. The final analysis included 1,470,313 tweets from Korea and 4,195,457 tweets from Japan; the daily Japanese tweets were limited because of their volume. Most Japanese citizens mainly use Twitter as SNS [16] rather than Facebook or Instagram, whereas the ranking of Twitter usage rate by Koreans is 7 th $(0.2 \%)$, which is relatively lower than Japan [17]. This may be due to the difference in populations: the current population of Japan $(126,264,931)$ is 2.4 times higher than Korea $(51,709,098)$ [18].

Based on the heat diagram analysis of the tweets, the words "Online", "Economy", and "Donation" had gradually reached a high rank since April 2020. Beginning March 1, elementary, middle, and high schools were temporarily closed and moved to online classes, which possibly affected the high ranks of "Online". The frequency of the word "Online" continuously increased after the Korean Ministry of Education announced an online education system on March 31 [19].
Citizens showed an interest in the economy, which is one of the major effects of COVID-19 in Korea. The economic growth rate $(-0.1 \%)$ had declined after COVID-19 compared to 2019 (2.0\%). This also affected Koreans' perceptions of the economy, reporting it as the most difficult economic time since the International Monetary Fund (IMF) intervention in 1998 [20].

The words "Travel" and "Postpone" were ranked high at the beginning of February 2020, but their ranks gradually decreased. "Travel" began to be rarely mentioned in tweets and disappeared from the rank list after February 25, indicating that Koreans had changed their opinions regarding traveling. The rapid spread of COVID-19 from the last week of February might have affected people's interest in traveling. The number of flights and travelers had sharply declined to $70.8 \%$, which provided an additional explanation for this trend [21]. Regarding "Postpone," school reopening and events were postponed for 1 to 2 months in the early stages of COVID-19; however, due to their continuous delay [19], people may have begun to lose interest in it.

In Japan, “COVID-19 (Corona)”, “Impact (影響)”, “Mask (マスク)”, “China (中国)”, “Response (対応)”, “Economy (経済)”, and “Government (政府)” were highly ranked be- 


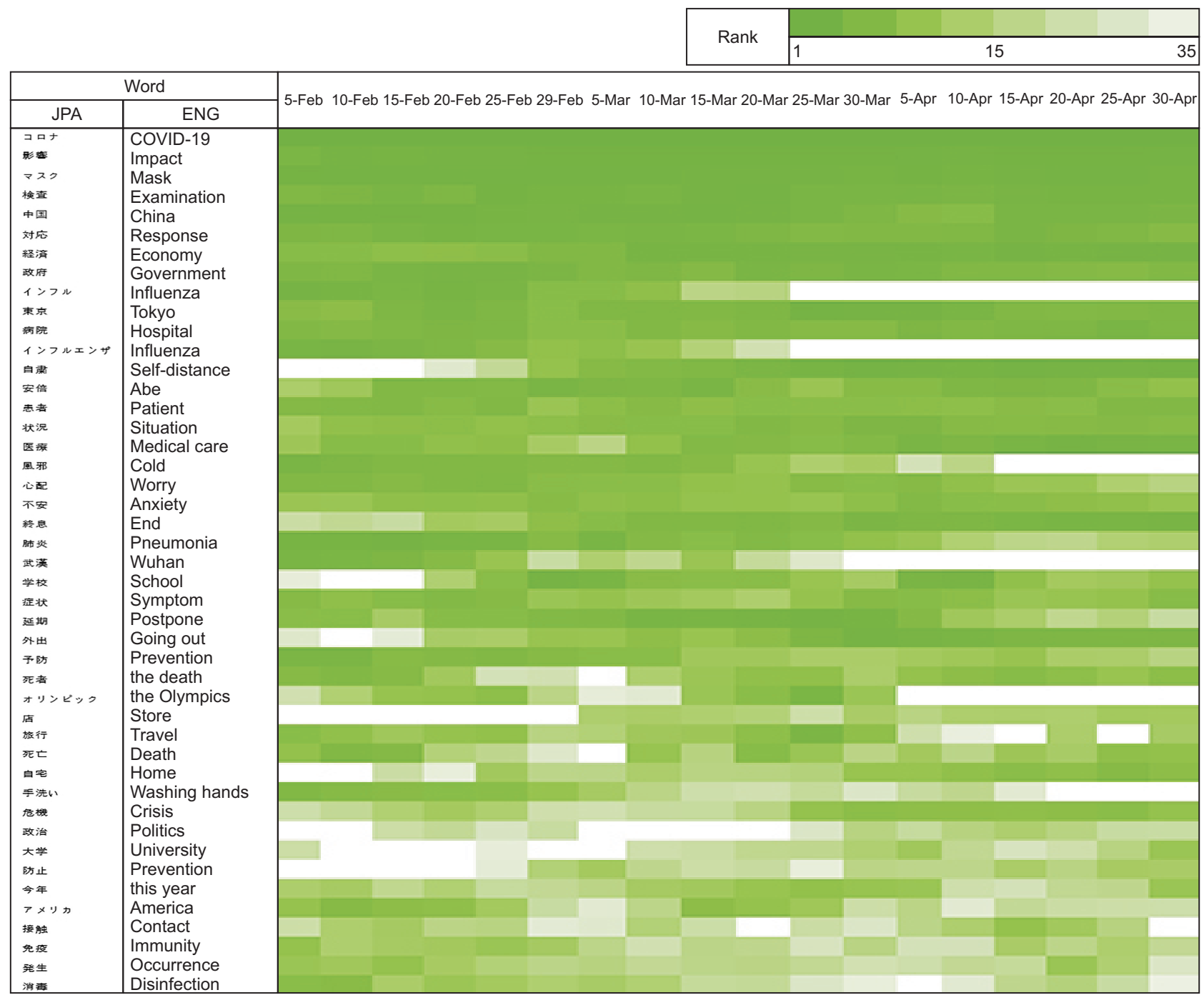

Figure 3. Heat diagram on the coronavirus disease 2019 (COVID-19) word trend in Japan from February 1, 2020 to April 30, 2020.

A

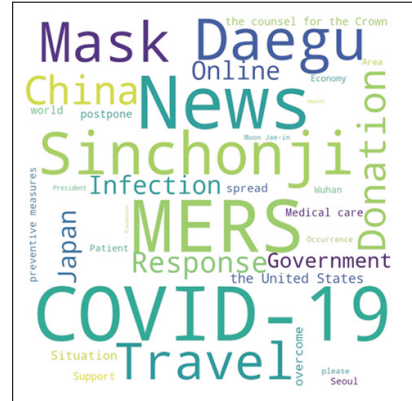

B

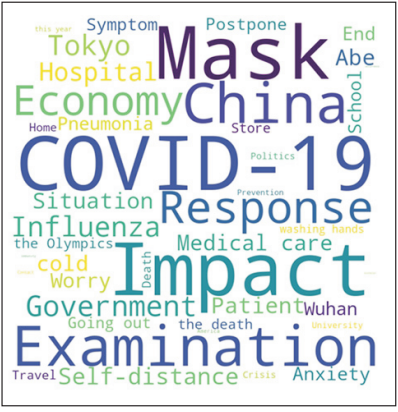

Figure 4. Word clouds based on tweets in Korea (A) and Japan (B).

tween February 5 and April 30. The Japanese government distributed two face masks per household on April 17, which generated significant public opinion and possibly affected the high rank of the word "Mask". Similar to Korea, Japanese citizens showed interest in their economy, reflecting their

difficult economic situation compared to 2019. The cancellation of the Olympics by Japan, the host country, may explain the continued increase in the rank of "Olympics". The rank of "Washing hands" decreased in March and then again increased since April, indicating people's interest in personal non-pharmaceutical interventions (NPIs). The Japanese government emphasized isolation and strict social distancing until March, and then promoted personal NPIs since April [22].

We divided the words into four categories, namely, social distancing, prevention, issue, and emotion, to analyze the rank flowcharts. Regarding social distancing, the word "World" began to increase in Korea since March 4, 2020, which is close to the time of a pandemic declaration by the World Health Organization (WHO). In Japan, contrary to the decreasing number of indicators related to going outside (traffic volume, using of public transportation, etc.), the 
Social distancing (KOR)

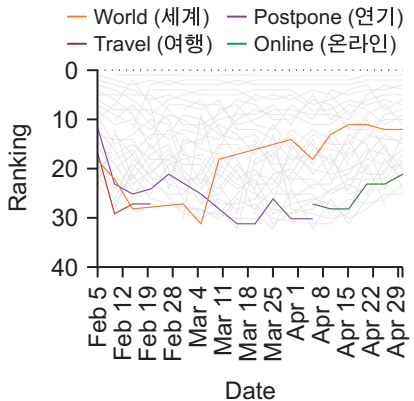

Social distancing (JPN)

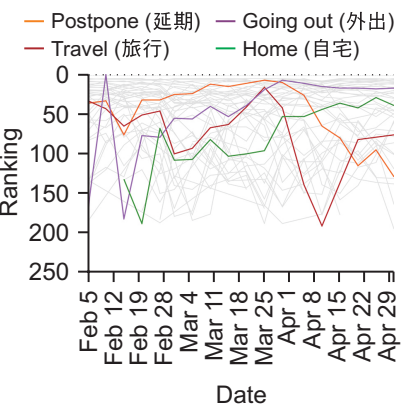

Prevention (KOR)

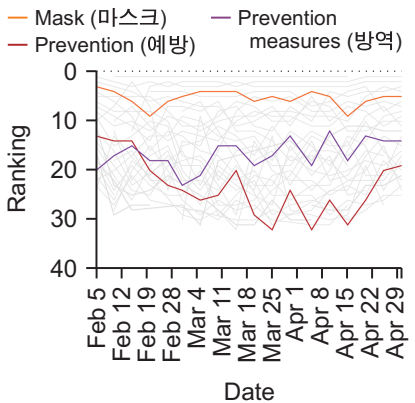

Prevention (JPN)

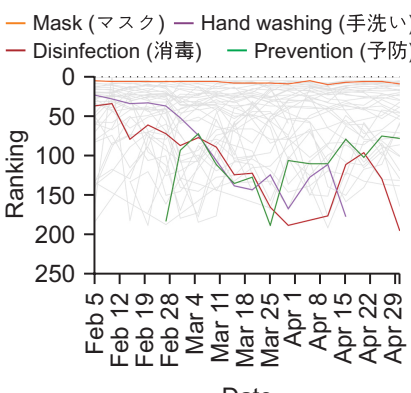

Issue (KOR)

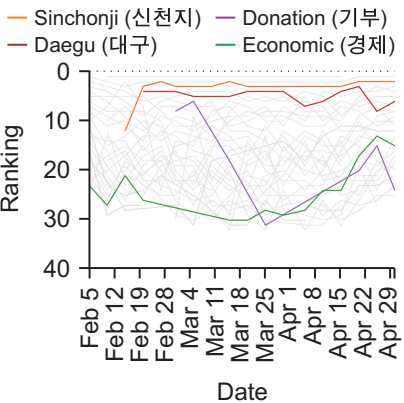

Issue (JPN)

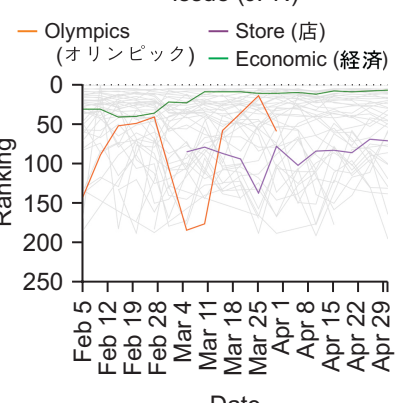

Emotion (KOR)

- Please (제발) - Support (자원)
- Overcome (극복) - Government (정부)

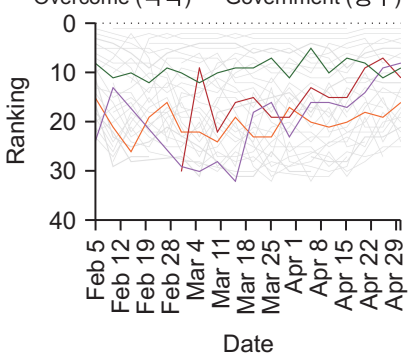

Emotion (JPN)

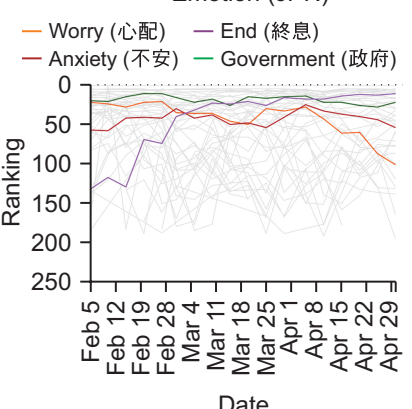

Figure 5. Rank flowcharts by four categories (social distancing, prevention, issue, and emotion) in Korea and Japan.

word "going out" had continuously increased since February 19th. Considering the request to stay home and close schools, the rank for the word "Postpone" continued to decrease and "Home" began to increase.

Regarding prevention, the high rank of "Mask" in both countries can be explained by the high compliance of wearing masks in Korea and Japan (Korea 78.7\%; Japan 77.0\%) [23]. In April, the words related to personal prevention began to rank higher compared to March, which showed a decline in ranks, thereby indicating citizens' increased interest in personal NPIs. This trend may be based on changes in policies of both governments, which shifted focus to personal hygiene from strict social distancing.

In Korea, after the government announced the disaster relief plan and people began donating for COVID-19 eradication, the rank of "Economic" and "Donation" increased on March 25. In contrast, the rank of "Olympics" in Japan decreased from March 25, the day Japan postponed the Olympics scheduled for 2020. The word "Store" emerged in the rank list from March 4. Some infected cases emerged in several stores during the first week of March, and Japanese local governments began to request stores to close temporarily from April, which may have affected this trend [24].

Concerning emotion, the rank of "Please" consistently increased in Korea. A previous study showed that people with high compliance of personal prevention experienced high psychological stress due to those who did not maintain the preventive practices [25], which might have affected the increasing numbers of tweets with requests to maintain preventive measures. Furthermore, the word "Please" was also associated with the wish to end the COVID-19 pandemic. We also observed the increasing ranks of "Overcome" and "Support", which reflected the current economic slump. In Japan, the citizens expected the COVID-19 pandemic to end since they mentioned the word "End" frequently. In contrast, the mention of the words “Worry (心配)” and “Anxiety (不 安)” decreased from April, which showed Japanese adaptations and insensibilities toward COVID-19. The WHO issued warnings about the possibility of a second pandemic after several countries eased their policies and citizens began to relax regarding COVID-19 [26].

This study has some limitations. First, it did not represent all age groups because the SNS was mainly used by the younger generation compared to the elderly generation. Second, although there are several SNS platforms such as Facebook, Never, Yahoo, Twitter, Instagram, KakaoTalk, and Band, we only collected posts from Twitter because of the API permission.

To minimize non-sampling error, we limited data collection to twitter although Naver in Korea and Yahoo in Japan are the most popular website. Future studies should analyze posts from various SNS to sufficiently represent the public opinion of each country.

In conclusion, this study analyzed the perceptions and 
emotions of Korean and Japanese citizens about COVID-19 to gain insight for future COVID-19 responses. The words in high frequencies were COVID-19, Shincheonji, Mask, Daegu and Travel in Korea, and COVID-19, Mask, Inspection, Capability and China in Japan. In both countries, COVID-19 and masks were frequently searched. As result of the rank flowchart, we observed that peoples' interests in the economy were high in both countries, which showed their worries about the economic downturn as a result of COVID-19 on twitter. Although interest in prevention increased since April in both countries, it also showed that the general public began to assuage their worries regarding COVID-19. We strongly suggest that psychological support strategies should be established in consideration of their various aspects of emotions.

\section{Conflict of Interest}

No potential conflict of interest relevant to this article was reported.

\section{Acknowledgments}

We would like to express our sincere gratitude to everyone in the world who is putting forth efforts to stop the COVID-19 pandemic.

\section{ORCID}

Hocheol Lee (https://orcid.org/0000-0003-1467-8843)

Eun Bi Noh (http://orcid.org/0000-0002-9867-127X)

Sea Hwan Choi (http://orcid.org/0000-0002-8573-362X)

Bo Zhao (http://orcid.org/0000-0002-6780-1633)

Eun Woo Nam (https://orcid.org/0000-0001-6584-0658)

\section{References}

1. Bedford J, Enria D, Giesecke J, Heymann DL, Ihekweazu C, Kobinger G, et al. COVID-19: towards controlling of a pandemic. Lancet 2020;395(10229):1015-8.

2. World Health Organization. Report of the WHO-China joint mission on coronavirus disease 2019 (COVID-19) [Internet]. Geneva, Switzerland: World Health Organization; 2020 [cited at 2020 Oct 8]. Available from: https://www.who.int/docs/default-source/coronaviruse/ who-china-joint-mission-on-covid-19-final-report.pdf 2020.

3. Bahn GH. Coronavirus disease 2019, school closures, and children's mental health. Soa Chongsonyon Chongsin Uihak 2020;31(2):74-9.

4. Shigemura J, Ursano RJ, Morganstein JC, Kurosawa M, Benedek DM. Public responses to the novel 2019 coronavirus (2019-nCoV) in Japan: Mental health consequences and target populations. Psychiatry Clin Neurosci 2020;74(4):281-2.

5. Rajkumar RP. COVID-19 and mental health: a review of the existing literature. Asian J Psychiatr 2020;52:102066.

6. Jacobson NC, Lekkas D, Price G, Heinz MV, Song M, O'Malley AJ, et al. Flattening the mental health curve: COVID-19 stay-at-home orders are associated with alterations in mental health search behavior in the United States. JMIR Ment Health 2020;7(6):e19347.

7. Jung SJ, Jun JY. Mental health and psychological intervention amid COVID-19 outbreak: perspectives from South Korea. Yonsei Med J 2020;61(4):271-2.

8. Ministry of Health, Labor and Welfare. Implementation of mental care for new coronavirus infections [Internet]. Tokyo, Japan: Ministry of Health, Labor and Welfare; c2020 [cited at 2020 Oct 8]. Available from: https://lifelinksns.net/.

9. Bartels SJ, Baggett TP, Freudenreich O, Bird BL. COVID-19 emergency reforms in Massachusetts to support behavioral health care and reduce mortality of people with serious mental illness. Psychiatr Serv 2020;71(10):1078-81.

10. Goldman ML, Druss BG, Horvitz-Lennon M, Norquist GS, Kroeger Ptakowski K, Brinkley A, et al. Mental health policy in the era of COVID-19. Psychiatr Serv 2020 Jun 10 [Epub]. http://doi.org/10.1176/appi. ps.202000219.

11. Bonanno GA, Galea S, Bucciarelli A, Vlahov D. What predicts psychological resilience after disaster? The role of demographics, resources, and life stress. J Consult Clin Psychol 2007;75(5):671-82.

12. Hechanova R, Waelde L. The influence of culture on disaster mental health and psychosocial support interventions in Southeast Asia. Ment Health Relig Cult 2017;20(1):31-44.

13. United Nations. Policy brief: COVID-19 and the need for action on mental health. New York (NY): United Nations; 2020 [cited at 2020 Oct 8]. Available from: https:// unsdg.un.org/resources/policy-brief-covid-19-andneed-action-mental-health.

14. Balabantaray RC, Mohammad M, Sharma N. Multiclass twitter emotion classification: a new approach. Int J Appl Inf Syst 2012;4(1):48-53. 
15. Chen S, Xu Y, Chang H. A simple and effective unsupervised word segmentation approach. Proceedings of the 25th AAAI Conference on Artificial Intelligence; 2011 Aug 7-11; San Francisco, CA. p. 866-71.

16. Fuchs T, SchAfer F. Normalizing misogyny: hate speech and verbal abuse of female politicians on Japanese Twitter. Japan Forum 2019;2019:1-27.

17. Oh YJ. Information search 'Naver' overwhelming 1st place, 'YouTube' usage significantly increased [Internet]. Seoul, Korea: Cosmetic Insight; c2020 [cited at 2020 Oct 8]. Available from: https://www.cosinkorea.com/mobile/ article.html?no=34894.

18. The World Bank. World Bank open data (Republic of Korea, Japan) [Internet]. Washington (DC): The World Bank; c2020 [cited at 2020 Oct 8]. Available from: https://data.worldbank.org/?locations=KR-JP.

19. Ministry of Education. Beginning of online education system for COVID-19 [Internet]. Seoul, Korea: 2020 [cited at 2020 Oct 8]. Available from: https://www.moe. go.kr/boardCnts/view.do?boardID=294\&boardSeq=801 $60 \&$ lev $=0 \&$ searchType $=S \&$ status $Y N=W$ \&page $=1 \& s=m$ oe\&m $=0204 \&$ op Type $=$.

20. Ahmad T, Haroon, Baig M, Hui J. Coronavirus disease 2019 (COVID-19) pandemic and economic impact. Pak J Med Sci 2020;36(COVID19-S4):S73-S78.

21. Statistica. Year-on-year change of weekly flight frequency of global airlines from January 6 to October 5, 2020, by country [Internet]. Hamburg, Germany: Statistica; c2020 [cited at 2020 Oct 8]. Available from: https:// www.statista.com/statistics/1104036/novel-coronavirusweekly-flights-change-airlines-region/.

22. Yabe T, Tsubouchi K, Fujiwara N, Wada T, Sekimoto Y, Ukkusuri SV. Non-compulsory measures sufficiently reduced human mobility in Japan during the COVID-19 epidemic [Internet]. Ithaca (NY): arXiv.org; 2020 [cited at 2020 Oct 8]. Available from: https://arxiv.org/ abs/2005.09423.

23. Miyazawa D, Kaneko G. Face mask wearing rate predicts country's COVID-19 death rates [Internet]. Laurel Hollow (NY): medRxiv.org; 2020 [cited at 2020 Oct 8]. Available from: https://doi.org/10.1101/2020.06.22.2013 7745.

24. NHK (Japan Broadcasting Corporation). "Request for leave" of each prefecture [Internet]. Tokyo, Japan: NHK; 2020 [cited at 2020 Oct 8]. Available from: https:// www3.nhk.or.jp/news/special/coronavirus/tokyo/.

25. Tan W, Hao F, McIntyre RS, Jiang L, Jiang X, Zhang L, et al. Is returning to work during the COVID-19 pandemic stressful? A study on immediate mental health status and psychoneuroimmunity prevention measures of Chinese workforce. Brain Behav Immun 2020;87:84-92.

26. Kurtenbach E, Hadjicostis M. WHO warns that 1st wave of pandemic not over, immediate 2 nd peak possible [Internet]. Dallas (TX): FOX4News; 2020 [cited at 2020 Oct 8]. Available from: https://www.fox4news.com/ news/who-warns-that-1st-wave-of-pandemic-not-overimmediate-2nd-peak-possible. 